\title{
Dorsal Herniation of Cauda Equina Due to Sequestrated Intradural Disc
}

\author{
Pradeep K. Singh ${ }^{1}$, Sandeep Shrivastava ${ }^{1}$, Rajesh Dulani ${ }^{1}$, Pankaj Banode ${ }^{2}$, Sharad Gupta ${ }^{1}$ \\ ${ }^{1}$ Department of Orthopaedics and Trauma, Datta Meghe Institute of Medical Science, Wardha, India \\ ${ }^{2}$ Department of Radiology, Technology Information, Forecasting and Assessment Council (TIFAC), Wardha, India
}

\begin{abstract}
Intradural lumbar disc herniation (ILDH) is uncommon pathology. In present report, authors present a case of ILDH associated with dorsal herniation of the cauda equina rootlets in a 30-year-old male laborer who had chronic backache since last two years. To the best of our knowledge we are reporting this for first time. Report demonstrates the natural course of ILDH.
\end{abstract}

Key Words: Intradural disc herniation, Duroplasty, Herniated cauda equina rootlets

\section{Introduction}

Intradural disc herniation is rare but known clinical entity incidence being around $0.26 \%$ to $0.30 \%$ of total cases of disc prolapsed [1-3]. The Common site for such pathology involve L4-L5 of lumbar spine. However, higher lumber spine disc herniation at L1-L2 and L2-L3 have also been reported in the literature [4]. Extruded intradural disc herniation produces significant clinical syndrome by compressing rootlets within the thecal sac. Dorsal herniation of the cauda equina roots due to extruded intradural disc has not been mentioned in the literature. We report an unusual case of a sequestered intradural lumbar disc herniation occurring at the L4-L5 pushing roots out of the dorsal duramater.

\section{Case Report}

This 30-year-old man, with a 2-year history of back pain, presented after 25 days of excruciating low back pain and weakness in his both lower limb following an attempt to lift a heavy weight. He had consistent cramp like discomfort over posterior aspect of the both side of leg. Examination of the spine revealed paravertebral muscle spasm and diffuse tenderness at the lumbar spine. Numbness was predominant over distal limb on both side. He reported significant weakness on both side of the lower limb to an extent that made him inability to walk and stand. He had no control over his bladder and bowel control. Flexion and extension of the spine was restricted and painful. Two year before presentation, patient had developed low back pain with radiation and weakness in both the lower limb He managed his daily activity with moderate discomfort. His bladder and bowel control was normal. He gradually recovered from acute backache episode over a period of two months time. Thereafter, he used to feel backache and radiating pain over both the lower limb. Now he presented to us with the features of cauda equina syndrome.

Neurological examination revealed grade 2/5 motor power in the knee extensor and grade $0 / 5$ at ankle on either side. His extensor hallucis longus had grade $0 / 5$ whereas flexor hallucis longus had grade $3 / 5$ motor strength on both the side. Knee jerk was diminished on either side where as ankle and planter reflex were absent. Hypoaesthesia were noted below knee over the medial shin and dorsum of the

Received Mar 7, 2011; Revised Apr 13, 2011; Accepted Apr 14, 2011

Corresponding author: Pradeep K. Singh, MD

Department of Orthopaedics and Trauma, Jawahar Lal Nehru Medical College and

Acharya Vinoba Bhave Rural Hospital, DMIMS, Wardha 442004, India

Tel: +91-7152-287701-05 (Ext. 358), Fax: +91-7152-287714, E-mail: drpradeepsingh@gmail.com

Copyright (C) 2012 by Korean Society of Spine Surgery which permits unrestricted non-commercial use, distribution, and reproduction in any medium, provided the original work is properly cited. Asian Spine Journal • pISSN 1976-1902 eISSN 1976-7846 

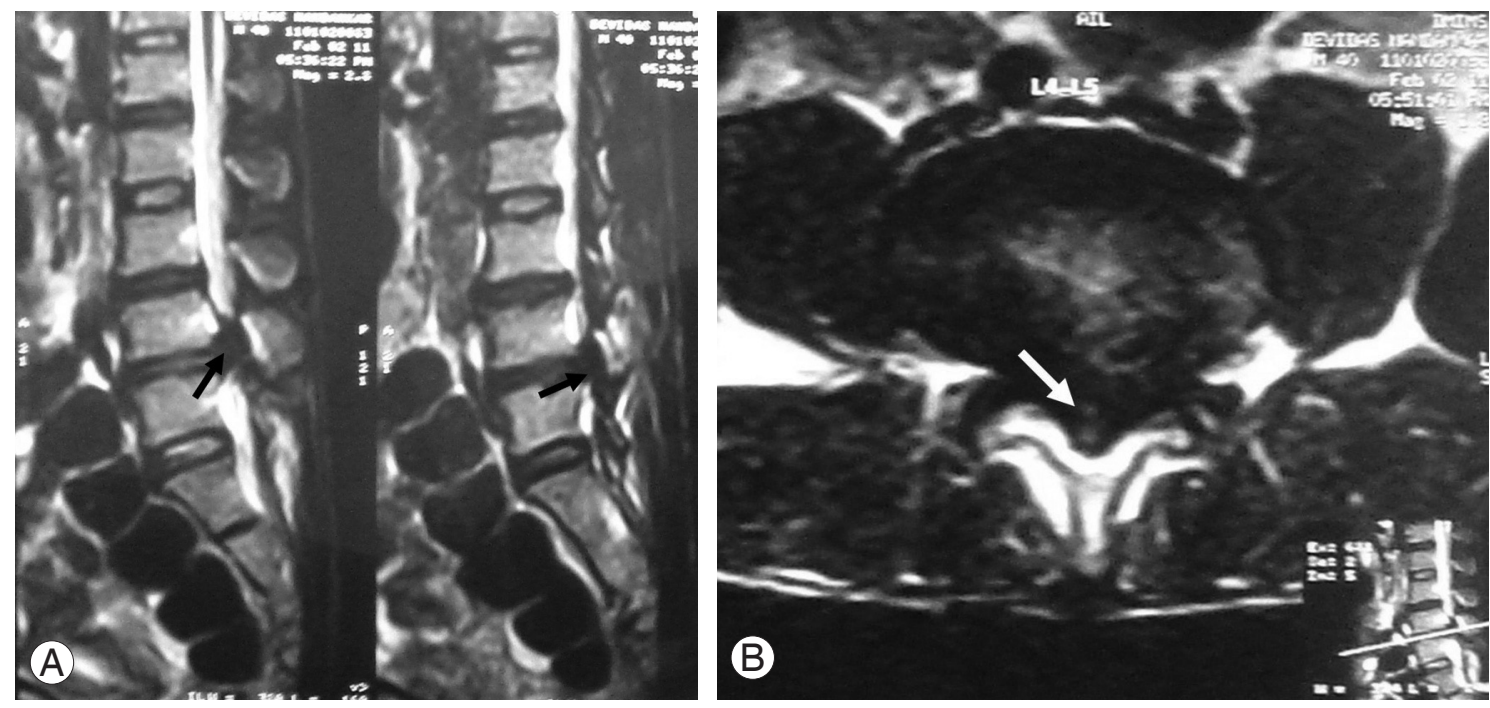

Fig. 1. (A) T2-weighted saggital magnetic resonance imaging at L4-L5 level of a 30 years old male shows thecal sac compression and hyperintense signals inside the sac (arrows). (B) T2- weighted axial section shows slightly hyperintense mass in central position in the dural sac (arrow).

foot on either side of the limb with perineal numbness. Bowel and bladder had no control. Anal and bulbocavernous reflex were absent. Sexual dysfunction was also concern of the patient.

A lumbar magnetic resonance imaging (MRI) demonstrates an well defined round intrathecal mass, very well depicted in the T1 and T2 WI (Fig. 1A). Axial MR slice (Fig. 1B) show significant compression of thecal sac at the level of L4-L5, with a central slightly hyperintense signals changes.

Subtotal laminectomy was performed at L4-5 level. Removal of lamina revealed torn dorsal duramater and herniated bunch of cauda equina roots (Fig. 2). Careful micro dissection of the roots showed sequestrated disc that was pushing roots out of the dorsal wall of the duramater. Ventral wall of the duramater was also found to be torn. At first, adhesiolysis and complete discectomy were performed. Ventral wall of duramater was repaired and dorsal defect of the duramater was reconstructed by doing duroplasty using autologus $2 \times 2 \mathrm{~cm}$ patch of posterior layer of thoracolumbar fascia from the operative site. Additionally, posterolateral bony fusion was performed.

A biopsy of the mass was sent for histo-pathological examination which showed disc material. The patient recovered uneventfully and exhibited complete remission of his neurological symptoms on follow up visits in a 3 months time.

\section{Discussion}

Intradural disc herniation has been consistently reported in the literature [1-3]. Although the pathogenesis of intradural disc herniation is not certain yet, still Blikra $[1,4,5]$ found the relationship between the ventral dura and the posterior longitudinal ligament (PLL) in form of dense adhesion throughout the lumbar spine. He concluded that

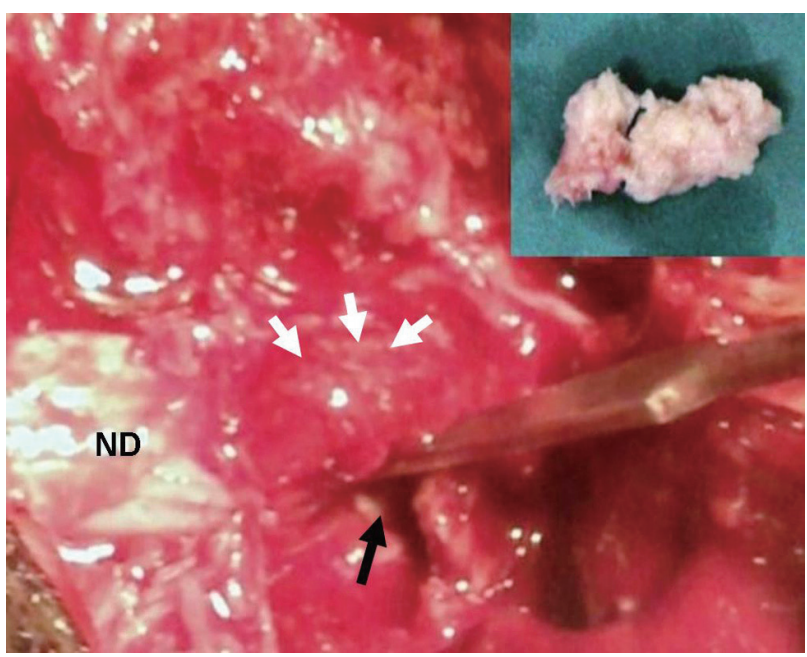

Fig. 2. A 30-year-old labour who had long standing backache presented with weakness, numbness with bowel bladder involvement since 12 days. The intra-operative finding showed cauda equine nerve rootlets displaced dorsally (multiple white arrows) by underneath intradural disc (inset). Black arrow illustrates the hollow space from where the disc was removed and white posterior longitudinal ligament. ND: Normal dura. 
non-separable adhesion between these structure could be the pathological basis of the intradural disc herniation [1,46]. Another study on cadavers demonstrated the presence of dural ligaments fixing the dura and nerve roots at their exit from the main dural sac to the posterior longitudinal ligament and vertebral body periosteum proximal to the intervertebral disc [7].

It has been studied that adhesions formed between ventral dura and PLL can be due to trauma, surgery, inflammation, osteophytes, disc protrusion fixed the dural sac or may be congenital $[6,8]$. Chronic herniated disc is another possible cause of adhesion which could be the reason in our patient. Chronic inflammation on herniated disc can cause adhesion and thinning of the dura, which eventually ruptures the dura thus herniation of disc in dural sac [8]. Disc herniation through both the anterior and posterior dural sac has also been observed [9]. Intradural disc can rupture the posterior dural sac depending on the size of nucleus pulposus [9]. Bigger size disc and chronic disc pathology explains herniation of disc across anterior and posterior dura sac in our case.

Gadolinium-enhanced MRI is the best modality for the precise diagnosis of intradural disc herniation $[7,10]$. Rim enhancement [7] and loss of continuity of PLL and sharp beak like appearance on T2-weighted images [10] are helpful radiological prediction for diagnosing intradural disc herniation.

Treatment of intradural disc is excision of disc and primary closure of defect. In most of the reports, ventral dural defect were closed primarily. Han et al. [8] closed ventral dural defect using dura-allograft. We closed ventral dural defect primarily and duroplasty using posterior layer of thoracolumbar fascia of the back for dorsal dural defect. Additionally, pedicle screw instrumentation and posterolateral bony fusion can be considered if wide laminectomy and facetectomy is in the plan of management [8].

We conclude that dorsal herniation of the cauda equina rootlet can be the sequlae of intradural disc. Autologus posterior layer of thoracolumbar fascia can be use for duroplasty of the defect.

\section{REFERENCES}

1. D'Andrea G, Trillò G, Roperto R, Celli P, Orlando ER, Ferrante L. Intradural lumbar disc herniations: the role of MRI in preoperative diagnosis and review of the literature. Neurosurg Rev 2004;27:75-80.

2. Aydin MV, Ozel S, Sen O, Erdogan B, Yildirim T. Intradural disc mimicking: a spinal tumor lesion. Spinal Cord 2004;42:52-4.

3. Epstein NE, Syrquin MS, Epstein JA, Decker RE. Intradural disc herniations in the cervical, thoracic, and lumbar spine: report of three cases and review of the literature. J Spinal Disord 1990;3:396-403.

4. Kataoka O, Nishibayashi Y, Sho T. Intradural lumbar disc herniation. Report of three cases with a review of the literature. Spine (Phila Pa 1976) 1989;14:529-33.

5. Blikra G. Intradural herniated lumbar disc. J Neurosurg 1969;31:676-9.

6. Yildizhan A, Paşaoğlu A, Okten T, Ekinci N, Aycan K, Aral O. Intradural disc herniations pathogenesis, clinical picture, diagnosis and treatment. Acta Neurochir (Wien) 1991;110:160-5.

7. Wasserstrom R, Mamourian AC, Black JF, Lehman RA. Intradural lumbar disk fragment with ring enhancement on MR. AJNR Am J Neuroradiol 1993;14:401-4.

8. Han IH, Kim KS, Jin BH. Intradural lumbar disc herniations associated with epidural adhesion: report of two cases. J Korean Neurosurg Soc 2009;46:168-71.

9. Reina EG, Calonge ER, Heriot RP. Transdural lumbar disc herniation. Spine (Phila Pa 1976) 1994;19:617-9.

10. Choi JY, Lee WS, Sung KH. Intradural lumbar disc herniation: is it predictable preoperatively? A report of two cases. Spine J 2007;7:111-7. 